\title{
CROSS CULTURAL ADAPTATION: KUESIONER STRATEGI MOTIVASI BELAJAR (MSLQ) SUBSSKALA EFIKASI DIRI DALAM BELAJAR DAN MENGERJAKAN TUGAS VERSI INDONESIA
}

\author{
Cross Cultural Adaptation: Motivated Strategies For Learning Questionaire (MSLQ) \\ Subscale Self Efficacy For Learning And Performance In Indonesian Version \\ Arief Budiman ${ }^{1}$, Elsye Maria Rosa ${ }^{2}$, Moh Afandi ${ }^{3}$ \\ ${ }^{1}$ Mahasiswa Program Studi Magister Keperawatan Program Pascasarjana UMY \\ ${ }^{2,3}$ Dosen Program Studi Magister Keperawatan Program Pascasarjana UMY \\ Email: arief b12@yahoo.com Telp: +62852 50842320
}

\begin{abstract}
ABSTRAK
Latar Belakang: Efikasi diri merupakan faktor penting dalam membentuk kemandirian belajar, efikasi diri berpengaruh terhadap motivasi, ketekunan dalam menghadapi kesulitan dan prestasi belajar, sebab itu dibutuhkan alat ukur untuk menilai efikasi diri yang valid dan reliabel. Dalam penelitian ini, cross cultural adaptation versi Indonesia dari MSLQ subscale self-efficacy for learning and performance digunakan untuk mengukur efikasi diri pada mahasiswa keperawatan.

Metode: Penelitian ini menggunakan 5 langkah cross cultural adaptation yaitu menterjemahkan, mensitesis, menterjemahkan balik selanjutnya hasil akhir kuesioner dalam versi Indonesia dinilai content validity index (CVI) dengan pertimbangan tiga ahli, kemudian diujicoba untuk melihat validitas dan reliabilitas pada mahasiswa diploma III keperawatan AKPER YARSI Samarinda yang berjumlah 88 mahasiswa

Hasil: Melalui tahap cross cultural adaptation terdapat penambahan jumlah item kuesioner dari 8 menjadi 27 item pernyataan dan berdasarkan nilai CVI menggunakan rumus Aiken`s V nilai koefisien seluruh item pernyataan $>0,5$, hasil uji validitas kuesioner seluruh item memiliki nilai signifikansi > 0,05 dan hasil uji reliabilitas kuesioner seluruh item memiliki nilai alpha cronbach > 0,6 .

Kesimpulan: kuesioner MSLQ subscale self-efficacy for learning and performance versi Indonesia memiliki Content Validity Index (CVI) yang memenuhi syarat dengan keseluruhan item valid dan reliabel sehingga dapat digunakan pada populasi target yaitu mahasiswa keperawatan.
\end{abstract}

Kata Kunci : Efikasi diri, MSLQ subscale self-efficacy for learning and performance, Pendidikan keperawatan

\begin{abstract}
Background: Self-efficacy is an important factor for establishing of learning independence, self efficacy gives influence to motivation, perseverance to overcome difficulties and learning achievement. Therefore a measuring instrument is needed to assess valid and reliable self efficacy. In this study cross cultural adaptation in Indonesian version from MSLQ subscale self-efficacy for learning and performance is used to to measure self efficacy of nursing students.

Method: This study used a five- steps cross cultural adaptation that are translation, synthesis, back translation and final questionnaire in Indonesian version is assesed content validity index (CVI) with consideration of three experts, than is tested to assess for validity and reliability to eighty-eight the nursing academy diploma students YARSI in Samarinda city.

Result: Through the stage of cross cultural adaptation there is have addition of the number of questionnaire items from 8 to 27 statement items and based on the value of CVI using the formula Aiken's V is obtained coefficient value of all item statement $>0.5$, the test results of the questionnaire validity of all item have significance value $>0.05$ and the questionnaire reliability of all item have alpha cronbach value $>0.6$
\end{abstract}


Conclusion: The MSLQ subscale self-efficacy for learning and performance instrument in Indonesia version has Content Validity Index (CVI) where is eligible with overall item are valid and reliable, so the instrument can be used in the target population of nursing students.

Key words : Self Efficacy, MSLQ subscale self-efficacy for learning and performance, Nursing Education

\section{Pendahuluan}

Seiring dengan perkembangan praktek dan pelayanan keperawatan, pendidikan keperawatan juga mengalami perubahan. Orientasi pendidikan keperawatan saat ini mengharuskan mahasiswa memiliki keuletan dan motivasi yang guna mencapai kompetensi yang ditetapkan. Membangun motivasi belajar peserta didik untuk senantiasa antusias dalam mengikuti proses pendidikan membutuhkan pengaturan diri yang baikatau dengan kata lain kemandirian belajar, faktor yang penting dalam membentuk kemandirian belajar seseorang yaitu efikasi diri. efikasi diri adalah keyakinan/kepercayaan serta ekspektasi seseorang dalam menghadapi tugasnya ${ }^{(1)}$. Berbagai studi menunjukkan self-efficacy berpengaruh terhadap motivasi, ketekunan dalam menghadapi kesulitan dari suatu tugas, dan prestasi belajar ${ }^{(9)}$.

Konsep efikasi diri memiliki implikasi dalam pendidikan keperawatan, literatur keperawatan mendukung peningkatan efikasi diri yang akan membantu menyatukan kesenjangan antara teori dan praktik $^{(3)(10)}$. Analisis dari konsep efikasi diri menyebutkan bahwa efikasi diri adalah sebuahvariabel kognitif yang mempengaruhi perilaku kinerja dan proses afektif. Seseorang merespon situasi berdasarkan persepsinya terhadap kejadian yang mempengaruhi perilaku serta kemampuan seseorang (4).

Sampai saat ini investigasi mengenai efikasi diri secara dominan mendukung peningkatan pengetahuan dan performance dalam pembelajaran kelas ${ }^{(11)(13)(14)}$. Sehinggajika kepercayaan diri mahasiswa terhadap kemampuan yang dimilikinya baik maka akan membantunya dalam meningkatkan prestasi belajarnya ${ }^{(6)}(12)$.

Pengukuran yang tepat terhadap efikasi diri ini merupakan hal yag perlu, bagaimanapun penggunaan instrument yang valid berdasarkan budaya lokalsangat penting. Motivated Strategies for Learning Quistionaire (MSLQ) merupakan instrumen penilaian diri yang disusun untuk mengukur orientasi motivasi mahasiswa di perguruan tinggi dan instrumen ini dapat digunakan pada strategi pembelajaran yang berbeda di perguruan tinggi. Terdapat dua bagian utama dalam kuesioner MSLQ, bagian motivasi dan bagian strategi pembelajaran. Namun untuk mengukur efikasi diri dapat menggunakan bagian efikasi diri dalam belajar dan mengerjakan tugas yang terdiri dari 8 item pernyataan.

Penilaian dalam kuesioner MSLQ subscale self-efficacy for learning and performance menggunakan 7 poin dengan skala likert dari "sama sekali tidak benar bagi saya" sampai "sangat benar bagi saya" nilai akhir individu dihitung dengan menjumlahkan seluruh skor item dan mengambil nilai rata-rata. Konsistensi reliabilitas internal dari kuisioener MSLQ subscale for learning and performance yaitu 0,93 dalam bahasa inggris.

Tujuan dari penelitian ini adalah untuk melakukan validasi terhadap kuesioner MSLQ subscale self-efficacy for learning and performance dalam area pendidikan keperawatan Indonesia.

\section{Metode Penelitian}

Di dalam penelitian ini menggunakan 5 langkah untuk melakukan cross cultural adaptation antara lain translation (menterjemahkan), synthesis (mensintesis), back translation (menterjemahkan balik), expert test (uji expert) and pilot testing (ujicoba) ${ }^{(7)}$. 


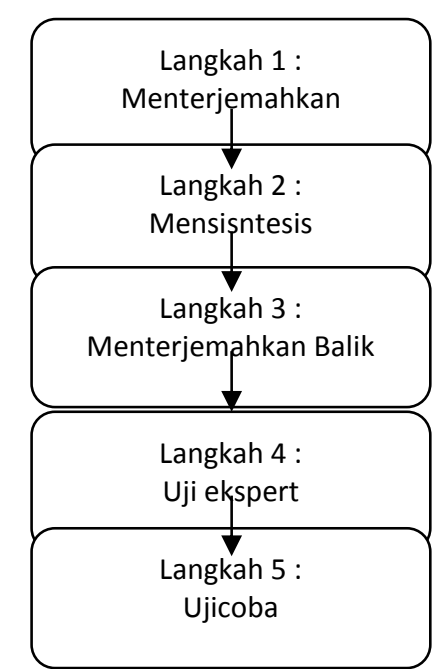

Gambar 1 Bagan alur proses cross cultural adaptation kuesioner MSLQ subscale self-efficacy for learning and performance

\section{Tahap pertama : translation (menterjemahkan)}

Pada tahap ini peneliti melakukan penterjemahan kuesioner dari bahasa inggris yang merupakan bahasa asli ke dalam bahasa indonesia, penterjemahan ini dilakukan di pusat pelatihan bahasa Universitas Muhammadiyah Yogyakarta

Tahap kedua : synthesis (sintesis)

Pada tahap kedua ini sinthesis dari item kuesioner dilakukan dengan melibatkan 3 ahli yaitu 1 ahli pendidikan dan 2 ahli pendidikan bahasa inggris.

\section{Tahap ketiga : back translation (Menterjemahkan kembali)}

Pada tahap ketiga kuesioner di terjemahkan kembali dari bahasa Indonesia ke bahasa inggris yang selanjutnya di konsultasikan kembali kepada 3 ahli untuk diterima dalam versi Indonesia, 1 ahli dari bidang teknologi pendidikan dan 2 ahli lainya dari bidang pendidikan bahasa inggris.

\section{Tahap keempat : expert test (uji expert)}

Pada tahap keempat dilakukan expert test kepada 3 ahli terhadap kuesioner efikasi diri dalam versi indonesia. Setelah itu dilakukan penilaian terhadap Content Validity Index (CVI)).

\section{Tahap kelima : pilot testing (ujicoba)}

Dalam ujicoba/pilot testing dalam penelitian ini sampel yang digunakan yaitu mahasiswa diploma III Keperawatan Akademi Keperawatan Yayasan Rumah Sakit Islam (YARSI) kota Samarinda yang berjumlah 88 orang. Selanjutnya hasil ujicoba dari kuesioner tersebut akan diuji validitas dengan melihat pearson correlation (sig. > 0.05) dan uji reliabilitas dengan melihat alpha cronbach (sig. > $0,60)$.

\section{Hasil}

Terdapat perubahan pada jumlah pernyataan pada tahap ke 2 yaitu melakukan sintesis kuesioner $M S L Q$ subscale self-efficacy for learning and performance, pada tahap ini jumlah item pernyataan mengalami penambahan dari 8 item menjadi 27 item pernyataan, adapun kisi-kisi kuesioner tersebut adalah sebagai berikut. 
Tabel 1. Kisi-kisi kuesioner

\begin{tabular}{clc}
\hline Dimensi & \multicolumn{1}{c}{ Indikator } & No \\
\hline Magnitude & $\begin{array}{l}\text { Keyakinan terhadap kemampuan dalam mengambil tindakan } \\
\text { yang diperlukan untuk mencapai suatu hasil }\end{array}$ & $5,7,9$ \\
\cline { 2 - 3 } & $\begin{array}{l}\text { Keyakinan terhadap kemampuan yang dimiliki untuk mengatasi } \\
\text { hambatan dalam tingkat kesulitan tugas yang dihadapi }\end{array}$ & $1,2,8$ \\
\cline { 2 - 3 } & Memiliki pandangan yang positif terhadap tugas yang dikerjakan & $3,4,6$ \\
\hline Generality & $\begin{array}{l}\text { Mampu menyikapi situasi dan kondisi yang beragam dengan } \\
\text { sikap positif }\end{array}$ & $20,22,25$ \\
\cline { 2 - 3 } & $\begin{array}{l}\text { Menggunakan pengalaman hidup sebagai suatu langkah untuk } \\
\text { mencapai keberhasilan }\end{array}$ & $21,23,24$ \\
\cline { 2 - 3 } & $\begin{array}{l}\text { Menampilkan sikap yang menunjukkan keyakinan diri pada } \\
\text { seluruh proses pembelajaran }\end{array}$ & $19,26,27$ \\
\hline Strength & $\begin{array}{l}\text { Memiliki keyakinan diri yang kuat terhadap potensi diri dalam } \\
\text { menyelesaikan tugas }\end{array}$ & $10,11,12$ \\
\cline { 2 - 3 } & $\begin{array}{l}\text { Memiliki semangat juang dan tidak mudah menyerah ketika } \\
\text { mengalami hambatan dalam menyelesaikan tugas }\end{array}$ & $13,14,17$ \\
\cline { 2 - 3 } & $\begin{array}{l}\text { Memiliki komitmen untuk menyelesaikan tugas akademik } \\
\text { dengan baik }\end{array}$ & $15,16,18$ \\
\hline
\end{tabular}

Selanjutnya pada kuesioner tidak ada perubahan sampai dilakukan ujicoba/ pilot testing pada mahasiswa Akademi keperawatan YARSI Samarinda. Adapun data karakteristik demografi responden dapat dilihat pada tabel dibawah ini.

Tabel 2. Data demografi responden

\begin{tabular}{lcc}
\hline Karakteristik Responden & N & \% \\
\hline Usia & & \\
1. 15-20 Tahun & 82 & 93,2 \\
2. 20 Tahun & 6 & 6,8 \\
\hline Jenis Kelamin & 12 & 13,6 \\
1. Laki-laki & 76 & 86,4 \\
2. Perempuan & & \\
\hline Suku & 36 & 40,9 \\
1. Jawa & 15 & 17,0 \\
2. Banjar & 16 & 18,2 \\
3. Kutai & 18 & 20,5 \\
4. Bugis & 1 & 1,1 \\
5. Dayak & 2 & 2,3 \\
6. Madura & & \\
Status Perkawinan & 2 & 2,3 \\
1. Kawin & 86 & 97,7 \\
2. Belum Kawin & &
\end{tabular}

Berdasarkan tabel 1 di atas karakteristik responden menurut usia, sebagian besar berusia 15-20 tahun yaitu sebanyak 82 orang $(93,2 \%)$ sedangkan usia > 20 tahun sebanyak 6 orang $(6,8 \%)$, selanjutnya berdasarkan jenis kelamin sebagian besar responden adalah perempuan sebanyak 76 orang $(86,4 \%)$ sedangkan responden laki-laki sebanyak 12 orang $(13,6 \%)$, berdasarkan suku, sebagian besar responden berasal dari suku Jawa yaitu sebanyak 36 orang (40,9\%), diikuti Bugis 18 orang (20,5\%), Kutai 16 orang (18,2\%), Banjar (17\%), Madura 2 orang (2,3\%) dan terakhir Dayak 1 orang $(1,1 \%)$, kemudian berdasarkan status perkawinan sebagian besar responden belum menikah yaitu sebanyak 86 orang $(97,7 \%)$ dan yang sudah menikah sebanyak 2 orang $(2,3 \%)$. 
Selanjutnya hasil content validity index (CVI) kuesioner MSLQ subscale self-efficacy for learning and performance yang dihitung menggunakan rumus Aiken`s $\mathrm{V}$ yang dilakukan di langkah ke 4 penelitian dapat dilihat pada tabel dibawah ini :

Tabel 3. Hasil perhitungan content validity index(CVI).

\begin{tabular}{cccc}
\hline $\begin{array}{l}\text { No. Item } \\
\text { Pernyataan }\end{array}$ & Koefisen Aiken`s V & $\begin{array}{c}\text { No. Item } \\
\text { Pernyataan }\end{array}$ & Koefisen Aiken`s V \\
\hline 1 & 0,77 & 15 & 0,66 \\
\hline 2 & 0,77 & 16 & 0,88 \\
\hline 3 & 0,77 & 17 & 0,77 \\
\hline 4 & 0,88 & 18 & 0,66 \\
\hline 5 & 0,55 & 19 & 0,88 \\
\hline 6 & 0,66 & 20 & 0,55 \\
\hline 7 & 0,66 & 21 & 0,66 \\
\hline 8 & 0,77 & 22 & 0,88 \\
\hline 9 & 0,55 & 23 & 0,88 \\
\hline 10 & 0,88 & 24 & 0,66 \\
\hline 11 & 0,88 & 25 & 0,88 \\
\hline 12 & 0,88 & 26 & 0,55 \\
\hline 13 & 0,77 & 27 & 0,66 \\
\hline 14 & 0,66 & & \\
\hline
\end{tabular}

Berdasarkan tabel diatas nilai koefisien Aiken`s V pada seluruh item pernyataan $>0,5$ hal ini berarti seluruh item pernyataan dalam kuesioner sudah dianggap memiliki validitas isi yang memadai.

Selanjutnya adapun hasil uji validitas dan reliabilitas item pernyataan kuesioner Strategies for Learning Questionaire (MSLQ) sebagai hasil uji di tahap akhir yaitu pilot testing dapat dilihat pada tabel dibawah ini

Tabel 4 Hasil uji validitas instrumen

\begin{tabular}{llllcc}
\hline No & Pearson correlation & Sig & No & Pearson correlation & Sig \\
\hline 1 & 0,706 & 0,00 & 15 & 0,889 & 0,00 \\
\hline 2 & 0,689 & 0,00 & 16 & 0,814 & 0,00 \\
\hline 3 & 0,774 & 0,00 & 17 & 0,717 & 0,00 \\
\hline 4 & 0,754 & 0,00 & 18 & 0,792 & 0,00 \\
\hline 5 & 0,697 & 0,00 & 19 & 0,768 & 0,00 \\
\hline 6 & 0,736 & 0,00 & 20 & 0,718 & 0,00 \\
\hline 7 & 0,771 & 0,00 & 21 & 0,853 & 0,00 \\
\hline 8 & 0,751 & 0,00 & 22 & 0,826 & 0,00 \\
\hline 9 & 0,799 & 0,00 & 23 & 0,846 & 0,00 \\
\hline 10 & 0,833 & 0,00 & 24 & 0,857 & 0,00 \\
\hline 11 & 0,788 & 0,00 & 25 & 0,833 & 0,00 \\
\hline 12 & 0,864 & 0,00 & 26 & 0,819 & 0,00 \\
\hline 13 & 0,835 & 0,00 & 27 & 0,842 & 0,00 \\
\hline
\end{tabular}

Berdasarkan tabel 4 diatas dapat disimpulkan bahwa nilai signifikansi seluruh item pernyataan pada kuesioner tersebut $<0,05$ yang artinya seluruh item pernyataan dalam kuesioner tersebut dinyatakan valid.

Berikutnya adalah hasil uji reliabilitas instrumen yang dapat dilihat pada tabel dibawah ini. 
Tabel 5 Hasil uji reliabilitas instrumen

\begin{tabular}{cccc}
\hline $\begin{array}{l}\text { No. Item } \\
\text { Pernyataan }\end{array}$ & Cronbach`s alpha & $\begin{array}{l}\text { No. Item } \\
\text { Pernyataan }\end{array}$ & Cronbach`s alpha \\
\hline 1 & 0,977 & 15 & 0,976 \\
\hline 2 & 0,977 & 16 & 0,976 \\
\hline 3 & 0,976 & 17 & 0,977 \\
\hline 4 & 0,976 & 18 & 0,976 \\
\hline 5 & 0,977 & 19 & 0,976 \\
\hline 6 & 0,977 & 20 & 0,977 \\
\hline 7 & 0,976 & 21 & 0,976 \\
\hline 8 & 0,976 & 22 & 0,976 \\
\hline 9 & 0,976 & 23 & 0,976 \\
\hline 10 & 0,976 & 24 & 0,976 \\
\hline 11 & 0,976 & 25 & 0,976 \\
\hline 12 & 0,976 & 26 & 0,976 \\
\hline 13 & 0,976 & 27 & 0,976 \\
\hline 14 & 0,976 & & \\
\hline
\end{tabular}

Berdasarkan tabel 5 diatas terlihat bahwa seluruh item pernyataan pada kuesioner memiliki nilai alpha cronbach > 0,60 artinya bahwa seluruh item pernyataan pada kuesioner tersebut dinyatakan reliabel.

\section{Pembahasan}

Di dalam penelitian ini keseluruhan item pernyataan dalam kuesioner MSLQ dapat diterima. Suatu kuesioner dapat diterima dan digunakan pada negara yang berbeda maka kuesioner tersebut harus diterjemahkan terlebih dahulu dan tepat divalidasi dalam kelompok target ${ }^{(8)}$, dalam hal ini kuesioner MotivatedStrategies for Learning Questionaire (MSLQ) subscale self-efficacy for learning and performance diubah kedalam versi bahasa Indonesia dengan kelompok target yaitu mahasiswa dalam bidang keperawatan.

Item kuesioner MotivatedStrategies for Learning Questionaire (MSLQ)subscale self-efficacy for learning and performance mengalami perubahan yaitu berupa penambahan item pernyataan dari 8 item menjadi 27 item pernyataan berdasarkan dimensi efikasi diri.

efikasi diri memiliki 3 dimensi yaitu Magnitude: dimensi ini terkait tentang tingkatan kesulitan tugas, Generality: dimensi ini berkaitan dengan keyakinan individu terhadap kemampuannya, Strength: dimensi ini terkait dengan kekuatan keyakinan seseorang terhadap kemampuannya ${ }^{(1)}$.

Pada tahap ujicoba menunjukkan bahwa item pernyataan kuesioner yang sudah diterjemahkan menampilkan penerimaan dari responden, hal ini ditunjukkan dalam penelitian (tahap ujicoba) yaitu tidak adanya prosentase missing dalam pengisian kuesioner. Gambaran hasil ujicoba terhadap kuesioner berdasarkan hasil uji validitas semua item kuesioner dinyatakan valid dan dapat diinterpretasikan bahwa hubungan tiap variabel dengan skor total variabel yaitu berada di rentang 0,689-0,889, dari nilai rentang tersebut dapat disimpulkan bahwa terdapat 15 item pernyataan kuesioner memiliki korelasi yang kuat dan 12 item pernyataan kuesioner memiliki korelasi yang sangat kuat. Kemudian berdasarkan hasil uji reliabilitas, nilai alpha cronbach dari item kuesioner berada di rentang 0,976-0,977 yang artinya semua item kuesioner dinyatakan reliabel.

Para penyusun instrumen Strategies for Learning Questionaire (MSLQ) mengklaim bahwa koefisien validitas terhadap item kuesioner kuat dan memiliki konsistensi yang baik ${ }^{(2)}$. Sejalan 
dengan pernyataan tersebut berdasarkan uji validitas dan reliabilitas terhadap 8 item kuesioner MSLQ semuanya dinyatakan valid dan reliabel.

\section{Kesimpulan}

Kuesioner MSLQ subscale self-efficacy for learning and performance versi Indonesia memiliki Content Validity Index (CVI) yang memenuhi syarat dengan keseluruhan item berjumlah 27 pernyataan yang valid dan reliabel. Kuesioner ini dapat digunakan untuk menilai efikasi diri pada responeden mahasiswa khususnya pada lingkung keperawatan.

\section{KEPUSTAKAAN}

Bandura A. Guide for constructing self-efficacy scales. Self-Effic Beliefs Adolesc. 2006;5(307-337). Pintrich PR. A conceptual framework for assessing motivation and self-regulated learning in college students. Educ Psychol Rev. 2004;16(4):385-407.

Kuiper R, Pesut D, Kautz D. Promoting the self-regulation of clinical reasoning skills in nursing students. Open Nurs J. 2009;3:76.

Robb M. Self-Efficacy With Application to Nursing Education: A Concept Analysis. In: Nursing forum [Internet]. Wiley Online Library; 2012 [cited 2017 Apr 8]. p. 166-172. Available from: http://onlinelibrary.wiley.com/doi/10.1111/j.1744-6198.2012.00267.x/full

Nilsen H. Influence on Student Academic Behaviour through Motivation, Self-Efficacy and ValueExpectation: An Action Research Project to Improve Learning. Issues Informing Sci Inf Technol. 2009;6.

Zulkosky K. Self-efficacy: a concept analysis. In: Nursing Forum. Wiley Online Library; 2009. p. 93-102.

Beaton DE, Bombardier C, Guillemin F, Ferraz MB. Guidelines for the process of cross-cultural adaptation of self-report measures. Spine. 2000;25(24):3186-3191.

Tomaszewski KA, Henry BM, Paradowski J, Kłosiński M, Walocha E, Golec J, et al. Cross cultural adaptation of the English version of the IOF-QLQ to Polish, to assess the health-related quality-of-life of patients after a distal radius fracture. Health Qual Life Outcomes [Internet]. 2015 Dec [cited 2018 Jan 19];13(1). Available from: http://hqlo.biomedcentral.com/articles/10.1186/s12955-015-0354-x

Pajares, F., \& Schunk, D.H. (2015). The self and academic motivation : Theory and research after the cognitive revolution. In

Kuiper, R. A., \& Pesut, D. J., 2004. Promoting cognitive and metacognitive reflective clinical reasoning skills in nursing practice : self-regulated learning theory. Journal of Advanced Nursing. 45(4), 381-391.

Nilsen, H., 2009. Influence on Student Academic Behaviour through Motivation, Self-Efficacy and Value-Expectation: An Action Research Project to Improve Learning. Issues Informing Sci. Inf. Technol. 6.

Riddell, T., 2007. Critical assumptions: thinking critically about critical thinking. Journal of Nursing Education. 46(3), 121-126.

Sinclair, B., Ferguson, K., 2009. Integrating simulated teaching/learning strategies in undergraduate nursing education. Int. J. Nurs. Educ. Scholarsh. 6.

Gloudemans, H.A., 2013. Critical thinking and self efficacy 